\title{
DIGITAL ENVIRONMENT FOR SINUSOIDAL VIBRATION TEST CONTROL OF AN AC POWER SOURCE-FED ELECTRODYNAMIC SHAKER
}

\author{
Leandro Della Flora and Hilton Abílio Gründling \\ Grupo de Eletrônica de Potência e Controle, UFSM. Santa Maria - RS - Brazil \\ 1della@mail.ufsm.br and ghilton@ctlab.ufsm.br
}

\begin{abstract}
This paper presents a digital environment for sinusoidal vibration test control of an AC power source-fed electrodynamic shaker. The proposed solution is based on a high performance switching-mode inverter with digital control obtained by means of a PC compatible platform. An interactive user interface software developed in the microcomputer offers an easy and automated execution of fixed frequency, swept sinusoidal, resonant search or personalized tests over a very wide frequency and test load mass range. The design considerations of the switching-mode power amplifier, modeling of the electrodynamic shaker, features of the control platform and the acceleration measuring system as well as experimental results are described in detail.
\end{abstract}

Keywords - Electrodynamic Shakers, Robust Adaptive Control, Sinusoidal Vibration Tests, Switching-Mode AC Power Sources.

\section{INTRODUCTION}

Mechanical vibration tests are usually performed to study the effects of vibration and evaluate physical properties of materials and structures. Application areas include aerospace, automobile and shipping industries, building, electronics, machine-tool and package. Most common uses are related to production control, frequency response, dynamic performance and environment tests [1].

The major task of vibration control is to let the table carrying the test specimen be accurately vibrated according to the command. For achieving this goal, test equipment normally employed consists of an electrodynamic vibration machine (shaker), a power amplifier and an acceleration controlling and monitoring system. Traditionally, electrodynamic shakers are fed by linear audio power supply with controlled voltage and frequency. This scheme usually results in high vibration performance due to its low distortion power, but also presents large size and weight and low conversion efficiency. It is known that the use of a switching-mode inverter replacing the linear one can avoid these disadvantages, but more sophisticated control is needed to reduce the effects of harmonics on vibration performance [2]. In [2]-[4], an accurate investigation indicated the existence of a deep frequency dependency on the shaker's armature electrical parameters owing to the wide frequency power excitation (typically, $5 \mathrm{~Hz}$ to $2 \mathrm{kHz}$ ). Mechanical parameters also change according to the test load, specially the mass. Resonances, modeling errors and unknown disturbances equally contribute to make almost unusual the

Manuscript received on May 29, 2006. First revision on August 18, 2006. Recommended by the Editors of the Special Section

José Antenor Pomilio and Andres Ortiz Salazar. open loop operation of vibration systems. In this case, the non-minimum phase characteristic of the plant restricts most of the available control strategies.

In general, vibration tests are performed based on guidelines defined by standards that are directly related to the nature of the test specimen. Particularly, there are well established recommendations such as type (sinusoidal or random) and levels of vibration. The period of the specimen's exposure commonly extends for hours and the need for resonant frequency identification definitely requires an automatic control system.

The market of vibration test environments provides many commercial systems. However, the effective real time and robust control characteristic on those equipments are not clear. The literature, on the other hand, reports only few papers concerning the acceleration control of inverter-fed electrodynamic shakers (see [2]-[8]). In [2], a sinusoidal acceleration analog controller for an electrodynamic shaker fed by a switching-mode power amplifier was presented. A current-controlled PWM inverter was designed and implemented. Then, an acceleration control scheme being capable of waveform and magnitude regulation was proposed. The feedback controller was augmented with a feedforward and a robust controller. In [3], similar scheme was applied for random vibration control. Good current and acceleration control characteristics were demonstrated by experimental results. However, particularly in [2], it's clear that the proposed solution is not quite insensitive to parameter variations. In addition, experimental tests performed with an extremely low mass capability shaker (lower than $1 \mathrm{~kg}$ ) are not suitable for evaluating the behavior of the proposed scheme under meaningful unpredictable resonances of the table.

In [9], a computer controlled switching-mode $\mathrm{AC}$ power source (ACPS) has been designed and implemented to feed an electrodynamic vibration machine. The proposed scheme uses a model reference repetitive algorithm to control the shaker's input voltage. Experimentally, good sinusoidal and harmonic voltage control characteristics were demonstrated. However, although the authors proposed an environment for random and sinusoidal vibration test control, there is no acceleration controlling or monitoring system.

Then, by adding an acceleration control loop to the ACPS voltage regulator proposed in [9], the feasibility of a sinusoidal acceleration controller based on the interaction of two control loops (one for the shaker's acceleration regulation and another for the ACPS output voltage control) has been finally verified in [4]-[7]. The proposed solution uses a robust model reference adaptive algorithm in the voltage control loop and an acceleration feedback controller augmented with a feedforward and a robust controller. The hardware configuration is similar to the one depicted in [9], 
except for including an acceleration measuring system. Good sinusoidal reference tracking performance and robustness in the closed loop control are verified experimentally over a very wide frequency and test load mass range. As an example of application, the proposed system is currently being employed at the Federal University of Santa Maria for vibration proof tests of mechanical parts and devices such as the exhaust pipes shown in figure 3(a).

To complement the controller solution presented in [7], this paper presents a detailed description of the automated and digitally implemented vibration test system, with special emphasis given to the switching-mode AC power source design considerations, modeling of the electrodynamic shaker and features of the control platform and acceleration measuring system. Experimental results and comparison to the original linear power amplifier are also provided.

\section{CONFIGURATION OF THE PROPOSED ELECTRODYNAMIC SHAKER SYSTEM}

The schematic diagram of the proposed switching-mode $\mathrm{AC}$ power source-fed electrodynamic shaker system is shown in figure 1. It consists of a single phase voltagecontrolled PWM inverter, a LC output filter and an electrodynamic vibration machine. The control strategy is executed in a PC-compatible platform and it is based on the interaction of two control loops: one for the acceleration regulation and another for the ACPS output voltage control. The acceleration loop generates the reference voltage $v_{0}{ }^{*}$ for the ACPS control loop. Only two variables, the output voltage $v_{o}$ and the vibration acceleration $a$, are measured.

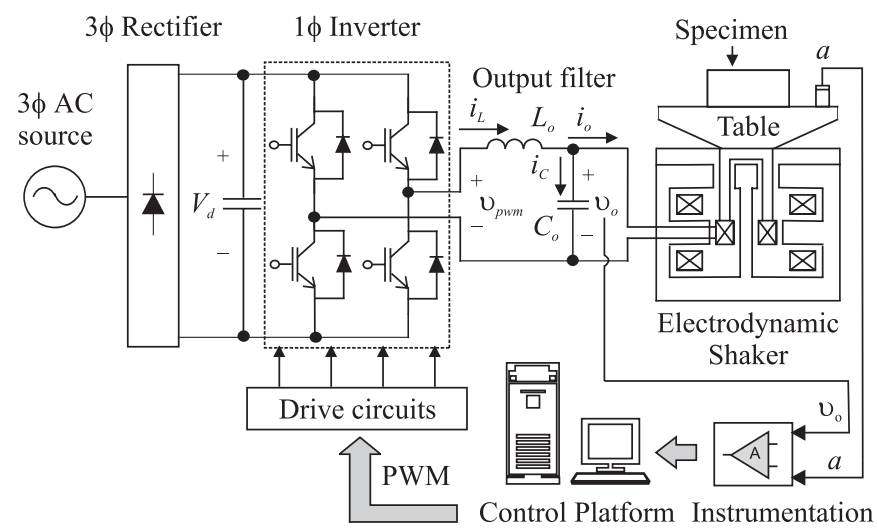

Fig. 1. AC power source-fed electrodynamic shaker.

\section{A. AC Power Source Parts and Devices}

The development of suitable amplifiers has constituted an important research interest area for shaker's manufacturers over the years. Linear power amplifiers address the requirements for low power distortion and high vibration performance, but the large size and weight and low conversion efficiency restricted their use to low power or more portable applications. Amplifiers for larger installations (whose rating extends to $300 \mathrm{kVA}$ ) generally employs switch-mode principles with extremely high switching frequencies to minimize distortion. In this case, high switching rates allow test frequencies greater than $4 \mathrm{kHz}$ at full power. Smaller electrodynamic shakers, on the other hand, use either linear or switching amplifiers, depending upon the power requirements [10].

Up to now, many power electronic and control techniques have been developed to lessen the harmonic effects of inverters on their loads. Although inverters for motor drives or power supplies possess good current or voltage tracking characteristics at low frequencies, their control performance at high frequencies are not verified. In addition, the effectiveness of these driving and control methods under active loads with back electromotive force (EMF) is still rarely performed [2].

Power amplifiers for electrodynamic shakers usually operate in constant voltage mode. The frequency response for a shaker driven by a constant voltage input shows that the response of the moving element and its suspension system is damped and make it easier to control. Constant current mode, on the other hand, gives the amplifier a high impedance output. This mode of operation is advantageous when closed loop control is not required and when the shaker is operated in its mid frequency range. Typical applications include structural excitation in modal testing, where the shaker delivers a nominal constant force [10]-[11].

In the present case, the proposed ACPS is designed to operate as a voltage source for the electrodynamic shaker. It consists of electrical and mechanical parts assembled into an industrial standard box (see figure 2). A $3 \mathrm{kVA}$ three-phase insulated transformer supplies an input rectifier and a soft starting circuit composed by resistors, contactors, contactbottom and timer relay is employed to protect the rectifier from the inrush current. The single phase full-bridge PWM inverter is composed by two IGBT modules manufactured by Semikron ${ }^{\circledR}$ (model SK30GB123). It is mounted on a SKB6I card and rated in $1200 \mathrm{~V}, 30 \mathrm{~A} @ 25 \mathrm{kHz}$. The switching frequency is set equal to $12 \mathrm{kHz}$ and a LC filter $(470 \mu \mathrm{H}$ and $15 \mu \mathrm{F})$ reduces the output voltage harmonic content. This configuration is able to generate sinusoidal voltage waveforms or sinusoidal with harmonics between $10 \mathrm{~Hz}$ and $1 \mathrm{kHz}$. The maximum amplitude is equal to $180 \mathrm{~V}$.

The ACPS and microcomputer's interface is provided by an internal board that converts the TTL level PWM control signals from the microcomputer to the input drive circuits of the inverter module. The output voltage $v_{0}$ is measured by means of a signal conditioner that converts the $-180 \mathrm{~V}$ to $180 \mathrm{~V}$ output voltage range to TTL levels needed for digital conversion in the microcomputer.

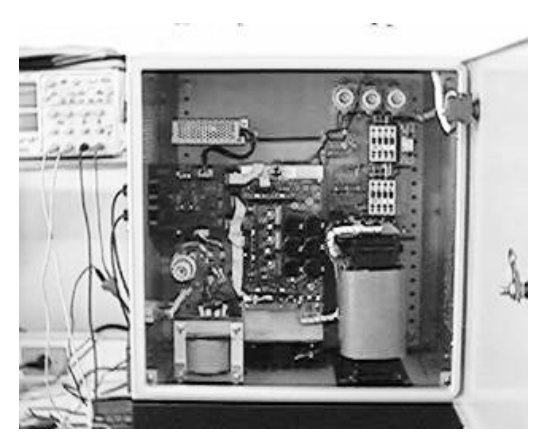

(a)

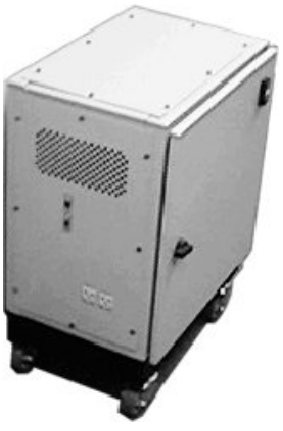

(b)
Fig. 2. The designed AC power source. 
Compared to the original shaker's linear power amplifier, there is a meaningful efficiency improvement (the former amplifier required approximately $10 \mathrm{kVA}$ to provide only 1 $\mathrm{kVA}$ for the vibration machine), smaller size (54 cm x $54 \mathrm{~cm}$ x $36 \mathrm{~cm}$ ) and reduced weight (approximately $50 \mathrm{~kg}$ ).

\section{B. Electrodynamic Vibration Machine}

The electrodynamic shaker (model St 5000/300 manufactured by TIRA) is a $1 \mathrm{kVA} / 110 \mathrm{~V}$ vibration machine capable to operate from $20 \mathrm{~Hz}$ to $5 \mathrm{kHz}$. The maximum sine force peak is $300 \mathrm{kp}(\approx 2940 \mathrm{~N})$ and the table's travel amplitude is rated at 0 to $6 \mathrm{~mm}$ at no load. The mass of the armature, table and fixture assembly is equal to $22 \mathrm{~kg}$ and the maximum specimen weight is $46 \mathrm{~kg}$.

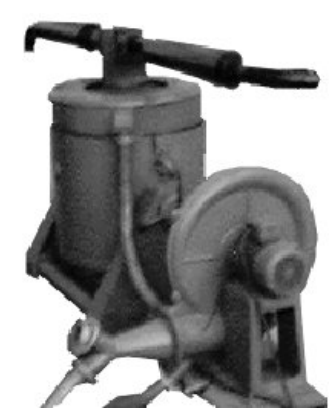

(a)

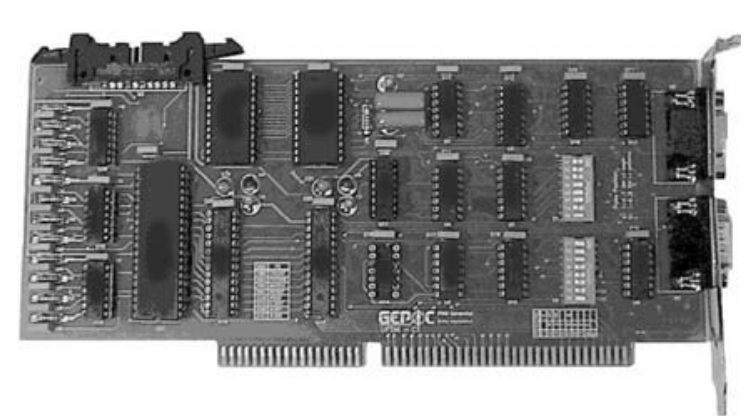

(c)

(b)

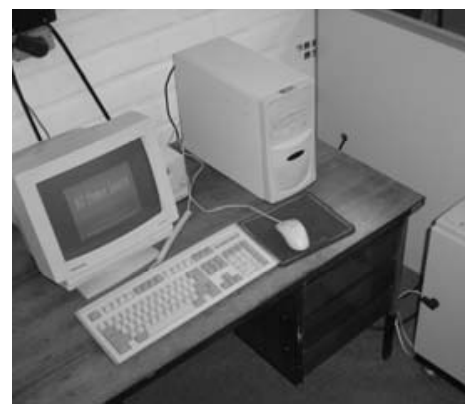

Fig. 3. Electrodynamic shaker with a test specimen (a), control platform (b) and multifunction interface board (c).

\section{PC Control Platform}

A multifunction interface board (figure 3(c)) is used to communicate the microprocessor and drive module. It includes two 12 bits $\mathrm{A} / \mathrm{D}$ converters at $12 \mathrm{kHz}$ sampling frequency, three 16 bits counters and three PWM signal generators. The software and hardware synchronization is carried out by the use of the three 16 bits counters. A program developed in Borland $\mathrm{C}$ programming language in the microprocessor acquires the external variables and computes the control law according to the specified vibration test. The control signal is converted into a PWM signal and then applied to the ACPS module through the multifunction interface board. Fixed frequency or swept sinusoidal closed loop vibration tests can be easily performed through an interactive user interface software in the microcomputer (figure 4). Resonant search or personalized tests are also available. The system provides data storage capability, input signal checks (rapid detection of control signal loss, input overload, open loop and other situations requiring a shutdown) and instantaneous emergency stop.

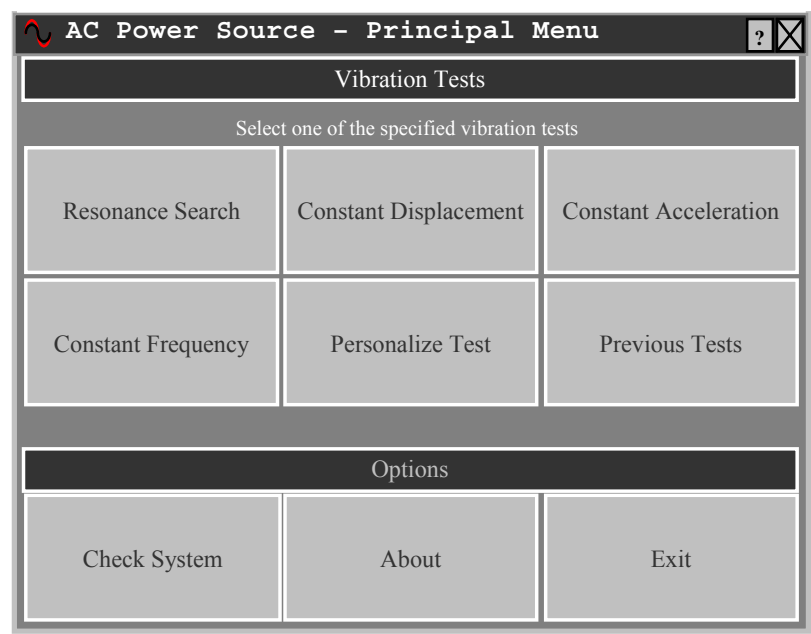

Fig. 4. The sine wave vibration control software main screen.

\section{Acceleration Measuring System}

Typical acceleration measuring systems for digital vibration test control are commonly composed by piezoelectric accelerometers (mounted on the shaker's table and the test specimen), preamplifiers, signal conditioning circuits, analog to digital converters (ADC) and tracking filters. Preamplifiers are needed to convert very weak output signals from high impedance piezoelectric sensors to low impedance measuring and analyzing instrumentation, which preserves the sensitivity and frequency response of the accelerometer. Signal conditioning is necessary to limit the upper and lower frequency in order to avoid interference from electrical noise or signals outside the linear portion of the accelerometer frequency range. It also provides extra amplification and anti-aliasing filtering for the ADC input. Analog to digital conversion is needed for digital processing and tracking filters allow that only the acceleration's fundamental component is used in the digital control process.

A general purpose accelerometer (model $4370 \mathrm{~V}$ manufactured by Brüel \& Kjaer) is employed to measure the shaker's acceleration (main specifications are indicated in table I). A charge mode preamplifier was designed to connect the output of the sensor to the input of the signal conditioner. Its charge sensitivity is equal to $8 \mathrm{mV} / \mathrm{g}\left(1 \mathrm{~g} \approx 10 \mathrm{~m} / \mathrm{s}^{2}\right)$. The frequency range of the signal conditioning circuit is $0.1 \mathrm{~Hz}$ to $10 \mathrm{kHz}$. A band-pass tracking filter is digitally implemented. Its center frequency tracks the sinusoidal acceleration reference and the quality factor is set equal to 0.35 .

TABLE I

Brüel \& Kjaer 4370V Piezoelectric Accelerometer

\begin{tabular}{lc}
\hline \multicolumn{2}{c}{ Technical Parameters } \\
\hline Charge Sensitivity & $10 \mathrm{pC} / \mathrm{m} / \mathrm{s}^{2}$ \\
Voltage Sensitivity & $8 \mathrm{mV} / \mathrm{m} / \mathrm{s}^{2}$ \\
Mounted Resonance & $16 \mathrm{kHz}$ \\
Frequency Range & $0.1 \mathrm{~Hz}-4800 \mathrm{~Hz}(10 \%)$ \\
Max. Transverse Sensitivity & $4 \%$ \\
Capacitance & $1200 \mathrm{pF}$ \\
Resistance & $20 \mathrm{G} \Omega$ \\
\hline \hline
\end{tabular}


The output of the proposed vibration measuring system swings from 0 to $5 \mathrm{~V}$ according to the table's acceleration. This signal is then converted by the multifunction interface board in the microcomputer and the acceleration is determined based on the mean sensitivity $(250 \mathrm{mV} / \mathrm{g} \pm 2 \%)$. Further details related to the design of the whole measuring system are to be appropriately reported in a next paper.

\section{DYNAMIC MODELING OF THE AC POWER SOURCE-FED ELECTRODYNAMIC SHAKER}

At a first level of approximation, the moving element of the electrodynamic vibration machine (i.e., the armature, table, fixture and test specimen assembly) can be modeled as a rigid body of mass $m$ supported by a suspension of constant stiffness $k$ and mechanical damping $c$ (see figure 5). In this case, the effect of the motional load on the AC power supply can be represented by the back electromotive force $e$ indicated in the equivalent circuit of figure 5.

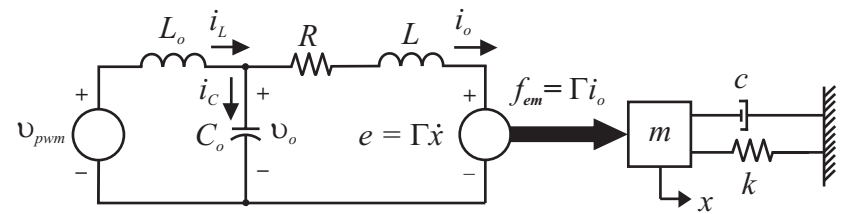

Fig. 5. Equivalent electromechanical circuit.

$\Gamma \triangleq B l$ is a force-generating constant.

$B$ is the magnetic flux density.

$l$ is the effective length of the armature conductors.

$f_{e m}$ is the linear force developed by the armature.

$i_{o}$ is the armature current.

$v_{\text {pwm }}$ is the inverter output voltage.

$i_{L}$ is the current of the output filter inductor.

$L_{O}$ is the inductance of the output filter.

$i_{c}$ is the current of the output filter capacitor.

$C_{o}$ is the capacitance of the output filter.

$v_{o}$ is the ACPS output voltage.

$L$ is the shaker's armature winding inductance.

$R$ is the shaker's armature winding resistance.

$x$ is the displacement of the armature.

$\dot{x}$ is the vibration velocity of the armature.

$a=\ddot{x}$ is the table's acceleration.

Perhaps, the most important component in the equivalent circuit is the motional back electromotive force $e$. Since $e=\Gamma \dot{x}$, the shape of the terminal voltage characteristic will initially tend to follow that of the velocity characteristic. However, for a constant amplitude sinusoidal acceleration $a$, the motional EMF dominance in the equivalent circuit fades as the frequency increases, owing to the continual decrease in velocity $(\dot{x}=a / \omega$, where $\omega$ is the vibration angular frequency). So the armature's winding reactance and resistance drops become significant and finally dominant. When the amplifier is unable to maintain current as coil impedance increases, the acceleration decreases apart from local, mechanical resonance-induced peaks. At very low frequencies ( 0 to $10 \mathrm{~Hz}$ ), suspension forces exceed $m a$ inertial forces, the inductance drops are negligible and the equivalent circuit approximates to $R$ in series with the EMF generator $e$. At the suspension mass-spring resonance (typically $20 \mathrm{~Hz}$ ), motion can be sustained with virtually no current. Beyond this point, the EMF generator has a value inversely proportional to the vibration frequency. Above $1 \mathrm{kHz}$ or so, the equivalent circuit can then be approximated to one comprising $R$ and $L$ in series. These parameters are not now constant due to skin effects.

The shaker's $v_{o}$ and $i_{o}$ characteristic changes from an inductive load at low frequencies to a capacitive nature over the mid frequency range. This behavior is unusual in electrical machines and poses interesting problems for the design of the supply amplifier. In addition, due to the finite axial stiffness of the moving element's structure, the rigidbody model is inadequate for high frequency operation because the relative axial motion between different parts of the moving element becomes significant in comparison with the motion of the moving coil itself. Indeed, axial resonances can be helpful in boosting table motion within certain frequency bands [10].

The complex nature involving resonances of the moving element at high frequency operation combined to electrical and mechanical parameters variations indicate that a robust control technique comprising reduced knowledge of the plant might be considered. In this case, the electrodynamic shaker can be approximately represented by the rigid body massspring system of figure 5 and the electrical and mechanical equations that govern the shaker's system can be written as

$$
\begin{gathered}
v_{p w m}=L_{o} \frac{d i_{L}}{d t}+v_{o} \\
v_{o}=L \frac{d i_{o}}{d t}+R i_{o}+e \\
C_{o} \frac{d v_{o}}{d t}=i_{c}=i_{L}-i_{o} \\
f_{e m}=\Gamma i_{o}=m \frac{d^{2} x}{d t^{2}}+c \frac{d x}{d t}+k x \\
e=\Gamma \frac{d x}{d t}
\end{gathered}
$$

In terms of parametric identification, the output filter inductance $\left(L_{o}\right)$ and capacitance $\left(C_{o}\right)$ as well the mass of the armature, table and fixture assembly $\left(m_{o}\right)$ are previously known as $470 \mu \mathrm{H}, 15 \mu \mathrm{F}$ and $22 \mathrm{~kg}$, respectively. $\Gamma, c, k, L$ and $R$, on the other hand, can be determined based on a simplified method similar to the one proposed in [2].

\section{A. Parameter Estimation of the Dynamic Model}

1) Identification of Mechanical Parameters $(\Gamma, c$ and $k)$ : according to equation (4), the transfer function $H_{I A}(s)$ from $i_{o}$ to $a$ can be expressed as

$$
H_{I A}(s) \triangleq \frac{a(s)}{i_{o}(s)}=\frac{\Gamma s^{2}}{m s^{2}+c s+k}
$$

At the suspension mass-spring resonance frequency $\omega_{o}$, equation (6) becomes

$$
H_{I A}\left(j \omega_{o}\right)=\frac{j \omega_{o} \Gamma}{c}, \quad \omega_{o}=\sqrt{k / m}
$$


and over the mid frequency range,

$$
H_{I A}(j \omega)=H_{I A}(\infty)=\frac{\Gamma}{m}, \quad \omega \gg \omega_{o}
$$

At no load condition $\left(m_{L}=0\right)$, the mass $m$ of the whole armature, table, fixture and test load is easily determined as

$$
m=m_{o}+m_{L}=22+0=22 \mathrm{~kg}
$$

Then, $\Gamma, c$ and $k$ can be identified as follows:

Step 1: measuring the frequency responses of $H_{I A}(s)$ (see figure 6 ), the suspension mass-spring resonance frequency $\omega_{o}$ is found $\omega_{o}=2 \times \pi \times 14.8 \mathrm{~Hz}$. Then, from equation (7):

$$
k=\omega_{o}^{2} m=190 \mathrm{kN} / \mathrm{m}
$$

Step 2: reading the value of $\left|H_{I A}(\infty)\right|, \Gamma$ is determined from equation (8):

$$
\Gamma=m H_{I A}(\infty)=280 \mathrm{~N} / \mathrm{A}
$$

Step 3: finally, the parameter $c$ is identified from (7) using the measured resonant peak $\left|H_{I A}\left(j \omega_{o}\right)\right|$ and the value of $\Gamma$ as:

$$
c=\omega_{o} \Gamma /\left|H_{I A}\left(j \omega_{o}\right)\right|=540 \mathrm{~N} / \mathrm{m} / \mathrm{s}
$$

The measured and simulated frequency responses of the electrodynamic shaker are plotted in figure 6. Although closeness is observed at low frequencies, the unmodeled high frequency resonance of the moving element indicates that, unless an appropriate robust acceleration control technique is employed, a rigid-body model is inadequate for high frequency operation. It should also be noted that the shaker's mechanical parameters are rather frequency independent within the frequency range, but the mass of the armature assembly changes according to the test specimen.

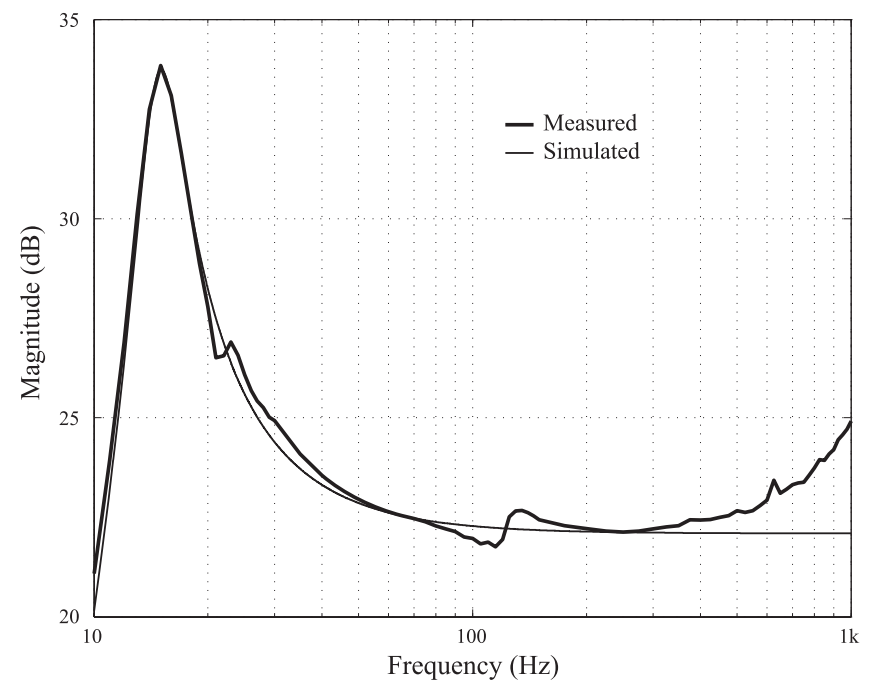

Fig. 6. Measured and simulated plots of $\left|H_{I A}(j \omega)\right|$.

2) Identification of Electrical Parameters ( $R$ and $L)$ : by letting $e=0$ (i.e., $\dot{x}=0$ ), the phasors of excitation voltage and the resultant current are related by $V_{o}=(R+j \omega L) I_{o}$. Thus, the armature resistance $R$ and inductance $L$ can be easily determined based on the amplitude and phase measurements of $v_{o}$ and $i_{o}$ at different frequencies. Figure 7 shows some experimental results within the range $10 \mathrm{~Hz}$ to 1
$\mathrm{kHz}$. The frequency dependent nature of $R$ and $L$ are clear from these results.
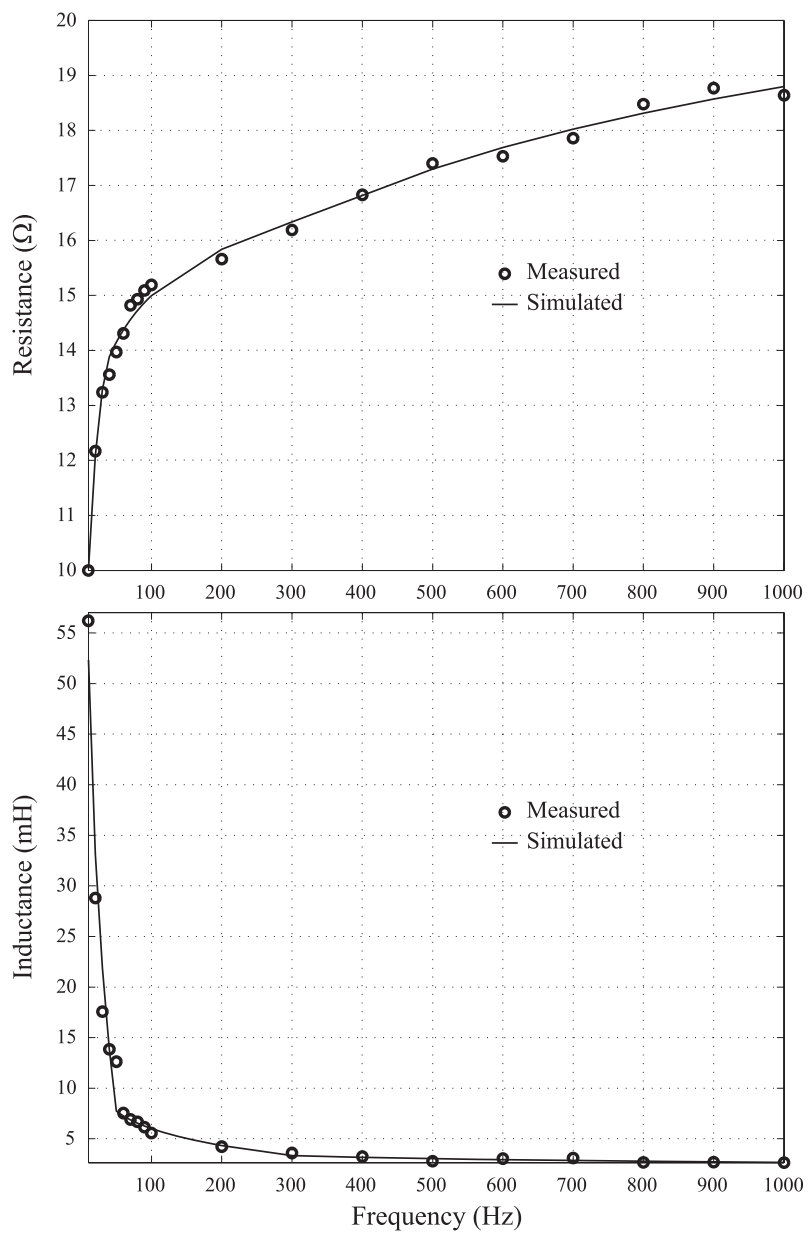

Fig. 7. Armature's measured and simulated $R$ and $L$.

\section{ACCELERATION CONTROL SYSTEM}

A high performance real time vibration control system for an electrodynamic shaker fed by a switching-mode power amplifier necessarily needs to deal with parameter variations on the plant, non-minimum phase characterized by the two poles at the origin of the $s$ plane (see equation (6)), harmonic vibrations effects introduced by the switching power supply, resonances of the moving element, modeling errors and unknown disturbances (represented mainly by the shaker's non-linear response).

Specifically in case of voltage fed electrodynamic shakers, the vibration control problem can be divided into an acceleration control loop interacting with the AC power source voltage regulator. Then, according to the reference $a^{*}$ and measurements of $a$ (figure 8), the acceleration controller generates the reference $v_{o}{ }^{*}$ for the ACPS controller.

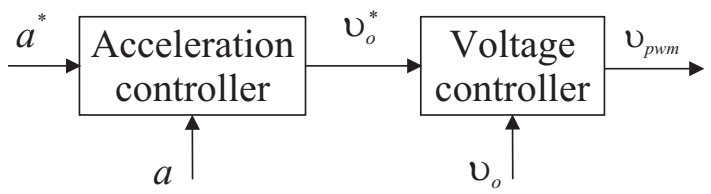

Fig. 8. Acceleration and ACPS voltage control loops. 


\section{A. AC Power Source Voltage Controller}

The main purpose of the voltage control loop is to regulate the $\mathrm{AC}$ power source output voltage based on the reference generated by the acceleration controller. In [9], a model reference repetitive algorithm has been applied to control the shaker's input voltage. Good experimental results indicated the effectiveness of the proposed scheme. However, since repetitive controllers have much more appeal on plants subjected to periodic disturbances [17], the prominent parametric variation and unmodeled dynamics characteristics assume, in this case, a ruling influence over the control technique decision.

Thus, by removing the repetitive control action and adding a robust and adaptive feature to the model reference controller proposed in [9], the RMRAC control scheme indicated in figure 9 is obtained to regulate the $\mathrm{AC}$ power source output voltage. It consists of a phase lead compensator (needed to move forward the phase of $v_{0}^{*}$ according to the high frequency delay produced by the reference model $W_{m}$ ), a recursive least squares algorithm to adapt the control parameter vector $\theta$ and a robust control law $u$. As demonstrated in [4]-[7], the resulting closed-loop system is stable and the plant output $v_{0}$ tracks the reference model output $y_{m}$ as closely as possible despite the unmodeled dynamics $\mu \Delta_{m}$ and $\mu \Delta_{a}$.

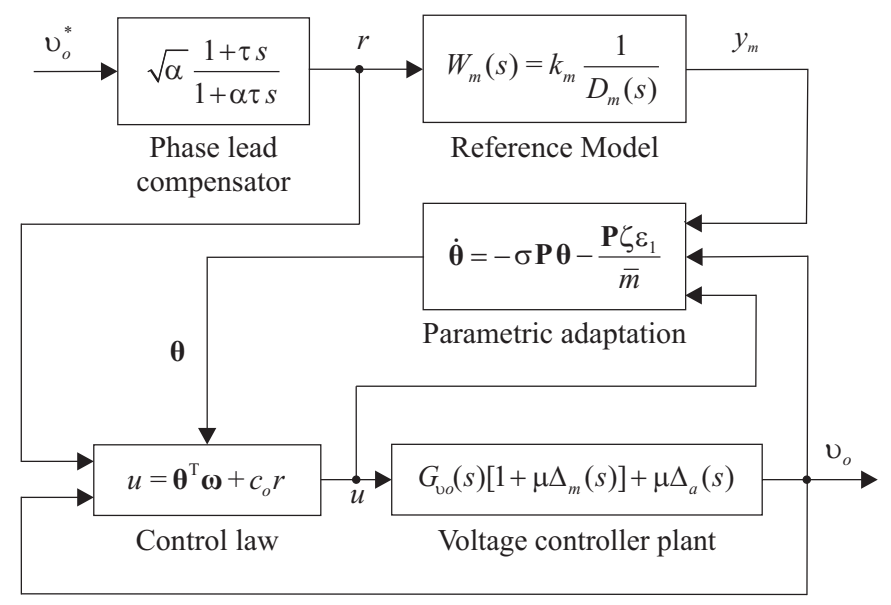

Fig. 9. The ACPS robust adaptive voltage controller.

\section{B. Acceleration Controller}

The shaker's acceleration $a$ is regulated according to the control scheme showed in figure 10. It consists of a feedback controller $G_{a b}$, a feedforward controller $G_{a c f}$ and a robust disturbance feedforward controller $G_{a d f}$. For analysis purposes, the bandpass filter transfer function $H_{b p f}$ can be considered unitary, i.e., $G_{a d f}=\omega_{a}$. Then, the voltage control loop reference $v_{o}^{*}$ is computed from

$$
v_{o}^{*}(s)=\frac{1}{1-\omega_{a}} G_{a b}(s)\left[a^{*}(s)-a(s)\right]+G_{a c f}(s) a^{*}(s)
$$

where $a^{*}$ is the acceleration controller's reference. In this case, the closed loop transfer function becomes

$$
\frac{a(s)}{a^{*}(s)}=\frac{\left[\left(1-\omega_{a}\right) G_{a c f}(s)+G_{a b}(s)\right] G_{a}(s)}{\left(1-\omega_{a}\right)+G_{a b}(s) G_{a}(s)}
$$

By letting $\omega_{a}=1$, an ideal control is obtained. However, to make a compromise between performance and stability, the weighting factor is tuned between $[0,1)$. Then, defining

$$
G_{a c f}(s)=\frac{1}{\overline{G_{a 0}}(s)} \triangleq-\frac{\bar{m} \bar{L} \bar{p}_{3}}{\bar{\Gamma}} \frac{\left(s-\bar{p}_{1}\right)\left(s-\bar{p}_{2}\right)}{s^{2}}
$$

where over bar line denote parameters at nominal case, $p_{1}$ and $p_{2}$ are the lowest poles of the shaker and $p_{3}$ is the faster pole, the closed loop transfer function approaches 1 even when the weighting factor is set different from the unity.

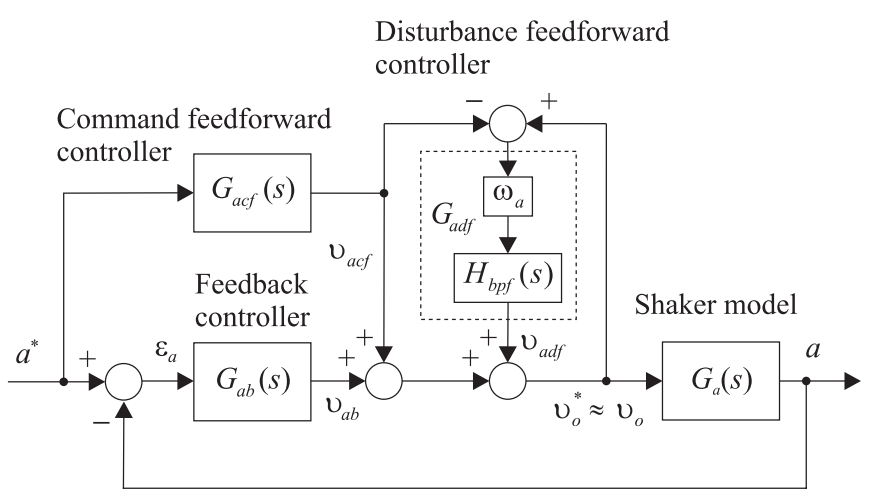

Fig. 10. The acceleration controller.

Details concerning the design and implementation of the proposed ACPS voltage and acceleration regulator are found in [4]-[7]. Specifically in [7], some modifications applied to the control scheme proposed in [4]-[6] resulted in the $1 \mathrm{kHz}$ high frequency control characteristic.

\section{EXPERIMENTAL RESULTS}

The feasibility of the proposed vibration acceleration controller has been verified by some experimental tests. Figures 11(a) and 11(b) show measured acceleration waveforms at two load and two frequency conditions $(0 \mathrm{~kg}$ and $15 \mathrm{~kg}, 20 \mathrm{~Hz}$ and $1 \mathrm{kHz}$ ). As indicated, the proposed solution is capable to achieve good fixed frequency reference tracking performance both in $20 \mathrm{~Hz}$ and $1 \mathrm{kHz}$ despite of the critical mechanical and electrical parameters variations presented. In this case, the lower and higher frequency limits are determined by the electrodynamic shaker and the actuator, respectively.

To verify the transient tracking response with frequency varying continuously, a constant amplitude acceleration has been employed to drive the electrodynamic shaker. Figures 12(a) and 12(b) show the corresponding measured acceleration results at $15 \mathrm{~kg}$ test load. Good dynamic tracking characteristics are observed from these results.

\section{CONCLUSION}

The development of an accurate vibration test control system for an electrodynamic shaker fed by a PWM inverter is a very important and challenged issue. Good acceleration tracking performance can only be obtained by using a control scheme capable to deal with parameter variations and nonminimum phase characteristic on the plant, harmonic vibrations effects introduced by the switching power supply, resonances of the moving element, modeling errors and 

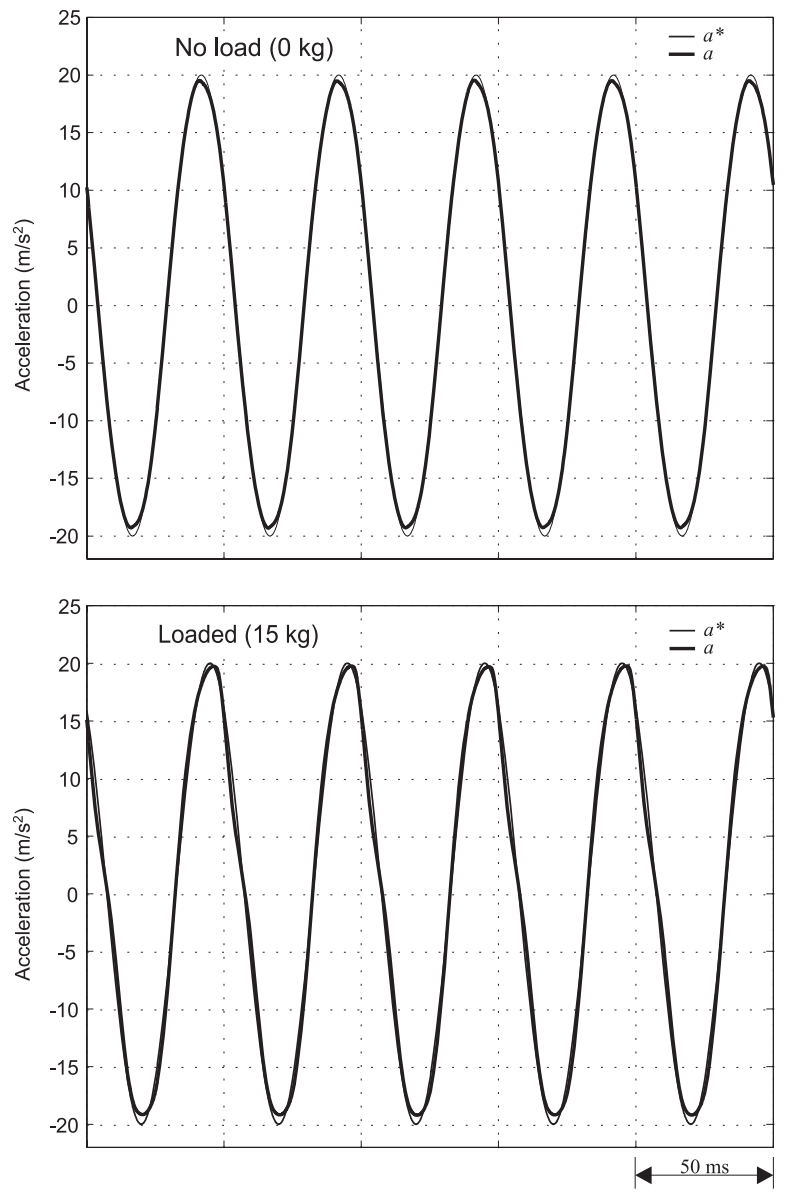

(a)
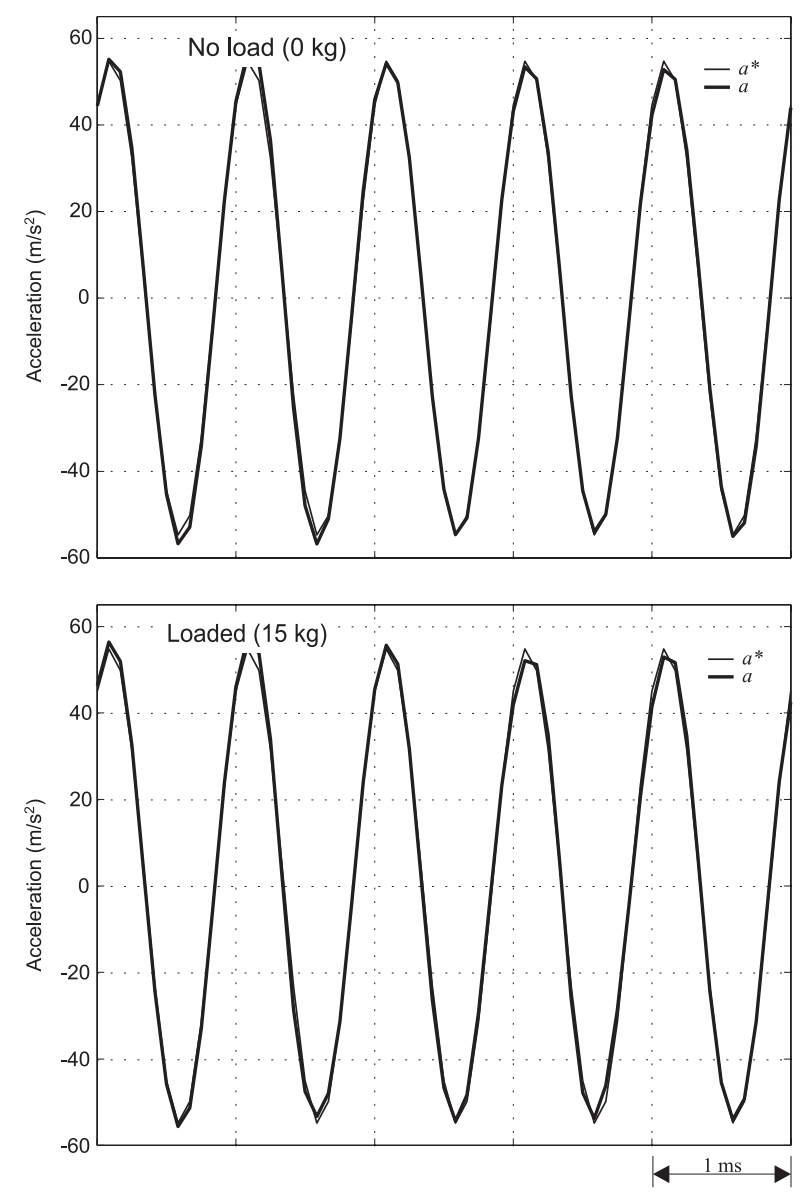

(b)

Fig. 11. Measured acceleration waveform $a$ and reference acceleration $a^{*}$. (a) $20 \mathrm{~Hz}$. (b) $1 \mathrm{kHz}$.

unknown disturbances. In this paper, an environment for sinusoidal vibration test control of an AC power source-fed electrodynamic shaker has been presented. The proposed solution is based on a high performance switching-mode inverter with digital control obtained by means of a PC compatible platform. Fixed or swept frequency, resonant search or personalized tests can be easily performed through an interactive user interface software in the microcomputer. Compared to the original vibration test system, there is a meaningful efficiency improvement, smaller size and weight and a very high flexibility gain represented by the digital implementation and substitution of the fixed analog controller.

Experimental results showed that this system is capable to achieve good sinusoidal acceleration reference tracking performance and robustness in the closed loop control. Current applications include vibration proof tests of mechanical parts and devices featuring very wide frequency and test load mass range. Topics for future researches include the development of a vibration test system capable to operate at higher and lower frequencies and also the development a random vibration controller.

\section{ACKNOWLEDGEMENT}

This work was supported by CNPq (Conselho Nacional de Desenvolvimento Científico e Tecnológico), FAPERGS
(Fundação de Amparo à Pesquisa do Estado do Rio Grande do Sul), UFSM (Universidade Federal de Santa Maria) and GEPOC (Grupo de Eletrônica de Potência e Controle).

\section{REFERENCES}

[1] C. M. Harris, Shock and Vibration Handbook, McGrawHill, $4^{\text {th }}$ Edition, New York, 1995.

[2] T. H. Chen and C. M. Liaw, "Vibration Acceleration Control of an Inverter-Fed Electrodynamic Shaker," IEEE/ASME Transactions on Mechatronics, vol. 4, pp. 60-70, March 1999.

[3] C. M. Liaw, W. C. Yu, and T. H. Chen, "Random Vibration Test Control of an Inverter-Fed Electrodynamic Shaker," IEEE Transactions on Industrial Electronics, vol. 49, pp. 587-594, June 2002.

[4] L. Della Flora, Controle de Aceleração de uma Máquina de Vibração Eletrodinâmica, Master's thesis, Universidade Federal de Santa Maria, Santa Maria, 2005.

[5] L. Della Flora and H. A. Gründling, "Vibration Acceleration Control of an AC Power Source-Fed Electrodynamic Shaker," in Proc. of $36^{\text {th }}$ Power Electronics Specialists Conference. Recife: IEEE, 2005, pp. 1175-1181.

[6] _ "Acceleration Control of an AC Power SourceFed Electrodynamic Shaker," in Proc. of $7^{\text {th }}$ Conferência 


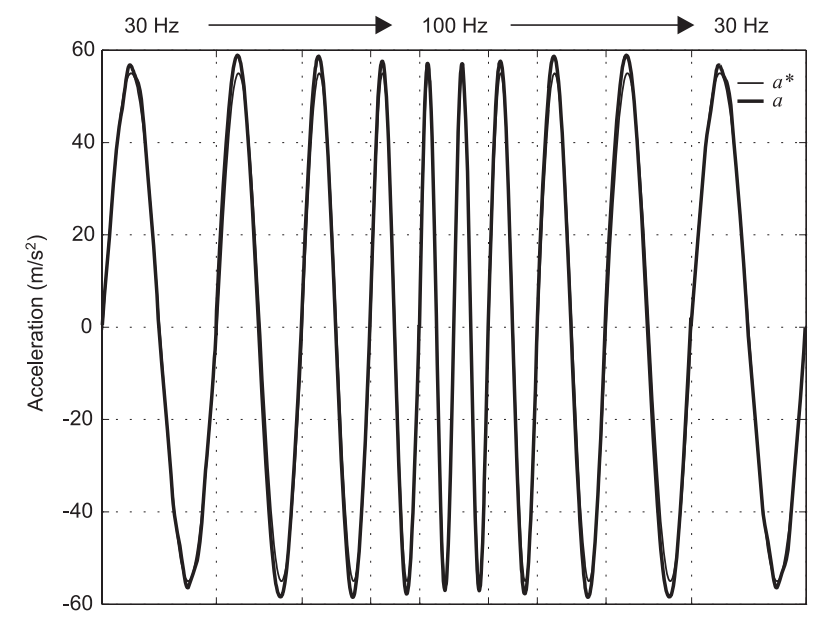

(a)

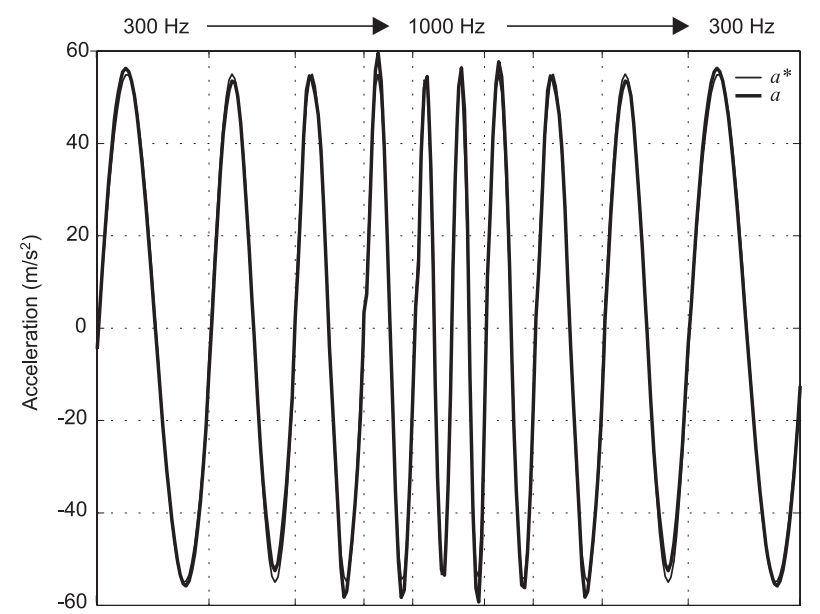

(b)

Fig. 12. Measured acceleration and reference with frequency variation at $15 \mathrm{~kg}$ load. (a) $30 \mathrm{~Hz}$ to $100 \mathrm{~Hz}$ (b) $300 \mathrm{~Hz}$ to $1 \mathrm{kHz}$

Internacional de Aplicações Industriais. Recife: IEEE, 2006.

[7] —, "Acceleration Control of an Inverter-Fed Electrodynamic Shaker," in Proc. of $37^{\text {th }}$ Power Electronics Specialists Conference. Jeju: IEEE, 2006, pp. 2799-2805.

[8] Y. Uchiyama, M. Mukai and M. Fujita, "Robust Acceleration Control of Electrodynamic Shaker Using $\mu$-Synthesis", in Proc. of the $44^{\text {th }}$ IEEE Conference on Decision and Control and the European Control Conference. Seville: IEEE, 2005, pp. 6170-6174.

[9] M. Stefanello and E. G. Carati, "Environment for Random and Sinusoidal Vibration Test Control of an Inverter-Fed Electrodynamic Shaker," in Proc. of International Symposium on Industrial Electronics. Rio de Janeiro: IEEE, 2003, pp. 1093-1098.

[10] R. Fair and H. R. Bolton, "Analysis and Design of Electromagnetic Moving Coil Vibration Generators," in Proc. of $6^{\text {th }}$ International Electrical Machines and Drives Conference. Oxford: IEEE, 1993, pp. 529-534.

[11]J. T. Broch, Mechanical Vibration and Shock Measurements, Brüel \& Kjaer, $2^{\text {nd }}$ Ed., Naerum, 1980.

[12] E. G. Carati, V. F. Montagner, and H. A. Gründling, "A Single-Phase AC Power Source Using Robust Model Reference Adaptive Control," in Proc. of Industrial Electronics Conference. Nagoya: IEEE, 2000, pp. 14281432.

[13] T. H. Chen, K. C. Huang, and C. M. Liaw, "A HighFrequency Switching-Mode Power Amplifier for Shaker Armature Excitation," IEE Proceedings Electric Power Applications, vol. 144, no. 6, pp. 415-422, 1997.

[14] J. Han, T. Tang and X. Wang, "A High-Performance Switching Mode Power Amplifier for Electrodynamic Shaker", in Proc. of International Conference on Industrial Technology. Hong Kong: IEEE, 2005, pp. 491-495.

[15]TIRA. Electrodynamic Shaker Model ST 5000/300: User's Guide. Schalkau, 1965.

[16]H. A. Gründling, Controle Adaptativo Robusto por Modelo de Referência, Ph.D.'s thesis, Instituto
Tecnológico de Aeronáutica, São José dos Campos, 1995.

[17]E. G. Carati, Controle Adaptativo Robusto por Modelo de Referência e Controle Repetitivo em Tempo Discreto: uma Abordagem Entrada/Saída, Ph.D.'s thesis, Universidade Federal de Santa Maria, Santa Maria, 2003.

[18]Environmental Considerations in Development of Mobile Agricultural Electrical/Electronic Components, ANSI/ASAE EP455, St Joseph, July 1991.

[19]P. A. Ioannou and J. Sun, Robust Adaptive Control, Prentice Hall, Upper Saddle River, 1996.

[20] K. J. Astrom and B. Wittenmark, Adaptive Control, Addison Wesley, London, 1989.

[21] I. D. Landau, R. Lozano, and M. M'Saad, Adaptive Control, Springer, New York, 1998.

\section{BIOGRAPHIES}

Leandro Della Flora was born in São Borja, RS, Brazil, in 1979. He received the B.S. and M.S. degree in electrical engineering from the Federal University of Santa Maria, Santa Maria, Brazil, in 2003 and 2005, respectively.

$\mathrm{He}$ is currently working towards the Ph.D. degree at the Federal University of Santa Maria. His areas of research interest include control systems and power electronics.

M. Eng. Della Flora is an active student member of the IEEE Control Systems Society.

Hilton Abílio Gründling was born in Santa Maria, RS, Brazil, in 1954. He received the B.S. degree from the Pontifical Catholic University of Rio Grande do Sul, Porto Alegre, Brazil, in 1977, the M.S. degree from the Federal University of Santa Catarina, Florianópolis, Brazil, in 1980 and the Ph.D. degree from the Technological Institute of Aeronautics, São Paulo, Brazil, in 1995.

Since 1980, he has been with the Federal University of Santa Maria, Santa Maria, Brazil, where he is currently a Professor. His research interests include robust model reference adaptive control, discrete control and control systems applications. 